\title{
Tensiones y contradicciones en torno a una ocupación de terrenos en un barrio de Mar del Plata. Apuntes para pensar el territorio en clave social

\author{
Tensions and contradictions surrounding an occupation of land in a \\ neighborhood of Mar del Plata. Notes to think the territory in social key
}

Federico Agustín Oriolani*

Recibido: mayo 03 de 2019

Aceptado: agosto 13 de 2019

\begin{abstract}
Resumen
El artículo discute las nociones de territorio y lugar a partir de una ocupación de terrenos en un barrio de la ciudad de Mar del Plata en 2018. Desde una perspectiva etnográfica, indagamos sobre las disputas y tensiones originadas en el proceso de apropiación territorial. Nos centramos en analizar las tramas de relaciones sociales y políticas que se anudan y desanudan en torno al conflicto, generadas por los diferentes actores sociales intervinientes y las acciones tendientes a reforzar o deslegitimar el hecho. Por un lado, planteamos que la noción de territorio atravesada por relaciones de poder y en conflicto no nos permite observar las múltiples identidades posibles dentro del grupo de familias que ocuparon los terrenos. En este sentido, creemos pertinente retomar los "sentidos del lugar" que imprimen una dinámica particular al territorio en disputa: el conflicto no implicó la conformación de identidades, pero sí la puesta en juego de significados del lugar relacionados con la experiencia previa de los actores. Por otro lado, a partir de la denuncia, observamos que se activan diferentes instancias para legitimar la ocupación; aquí surge una categoría que tiende a homogeneizar a las familias: la de "madres desempleadas con muchos hijos a cargo" enmarcadas en una "lucha por el acceso a la tierra". Consideramos que estas categorías invisibilizan el fenómeno, motorizado por la posibilidad alternativa de acceso a la tierra.
\end{abstract}

Palabras clave: disputas territoriales, política, sentidos del lugar, acceso a la tierra, legítimo ocupante.

\begin{abstract}
The article discusses the notions of territory and place from an occupation of land in a neighborhood of the city of Mar del Plata, in 2018. From an ethnographic perspective, we investigate around the disputes and tensions originated in the process of territorial appropriation. We focus on analyzing the webs of social and political relations that are knotted and unraveled around the conflict, generated by the different intervening social actors and the actions tending to reinforce or delegitimize the fact. On the one hand, we argue that the notion of territory crossed by power and conflict relations does not allow us to observe the multiple possible identities within the group of families that occupied the land. In this sense, we believe it is appropriate to return to the "senses of place" that imprint a particular dynamic on the disputed territory: the conflict did not imply the formation of identities but, rather, the putting into play of meanings of the place related to the previous experience of the actors. On the other side, from the complaint, we observed that different instances are activated to legitimize the occupation. Here, a category emerges that tends to homogenize families: that of "unemployed mothers with many dependent children" framed in a "struggle for access to land". We believe that these categories make the phenomenon invisible, driven by the alternative possibility of access to land.
\end{abstract}

Keywords: territorial disputes, politics, sense of place, access to land, legitimate occupant. 


\section{Introducción}

El siguiente artículo presenta avances preliminares de una investigación en curso más amplia, centrada en dar cuenta de las estrategias habitacionales de sectores populares en barrios periurbanos de la ciudad de Mar del Plata, en el periodo de 2009 a la actualidad. En mayo, diferentes portales web locales informaron sobre la toma de terrenos en Nuevo Golf (NG) por un grupo de familias. El hecho lo denunció el presidente de la sociedad de fomento del barrio (PSF) ante el municipio que presentó el reclamo en la Fiscalía No. $12 .{ }^{1}$ Trascendieron distintas versiones de la acción; algunos medios pusieron el foco en la ilegalidad del caso y en la característica jurídica del espacio -en los mapas figuraba como "plaza"-. Otros medios mostraron el hecho como parte del problema habitacional, agudizado con la crisis del puerto. A partir de allí, se estableció contacto con los diferentes actores del conflicto y se participó en las reuniones de las familias que tomaron los terrenos; así como con otras instancias fuera del territorio en cuestión, con el fin de participar en actividades de las organizaciones intervinientes.

En este caso, se aborda la productividad social del conflicto (Melé, 2016) en torno a las estrategias de acceso a la tierra de un grupo de familias en un barrio periférico de la ciudad de Mar del Plata. La denuncia realizada por el PSF volvió el hecho de carácter público, provocando diferentes instancias de identificación social y territorial. Se analizan las tramas de relaciones sociales y políticas que se anudan y desanudan en torno al conflicto, generadas por los diferentes actores sociales intervinientes y las acciones tendientes a reforzar o deslegitimar el hecho.

No sólo se pretende comprender las condiciones de posibilidad de la ocupación, sino también la denuncia como una acción que nos habla de la historicidad barrial, de las trayectorias de los referentes y de la dimensión política y jurídica de los territorios. Para ello, se retoman las categorías de territorio y lugar para pensar el conflicto urbano. ¿Alcanzan estos conceptos para comprender los fenómenos aquí estudiados? ¿Son multiterritorios-lugares territorializados? ¿Qué visiones del territorio se ponen en juego? ¿Estos territorios de exclusión urbana son producidos por medio de los conflictos territoriales imprimiéndoles una identidad al lugar? ¿El conflicto produce identidades y territorios?

En primer lugar, se delimitan conceptualmente algunas consideraciones sustanciales sobre las categorías de territorio, lugar y conflicto; en un segundo apartado, se aborda el contexto local y barrial que forma parte de las condiciones de posibilidad de emergencia del hecho. Posteriormente, se analizan los diferentes actores sociales implicados y la productividad social del conflicto.

${ }^{1}$ La Fiscalía No. 12 fue creada en 2014 para encargarse de las denuncias de usurpación de propiedad, debido al gran número de hechos. 
La propuesta se desarrolló bajo la perspectiva etnográfica. Se realizaron entrevistas informales y en profundidad -semiestructuradas- a diferentes actores sociales -referentes barriales, vecinos, funcionarios públicos- y se participó en actividades y reuniones organizadas por las familias que tomaron los terrenos.

\section{Pensar el conflicto en torno a las nociones de territorio y lugar}

En el abordaje aquí propuesto nos focalizamos en los efectos generados por los conflictos urbanos. Simmel (2010) destaca que los conflictos no sólo producen crisis, sino también son generadores de socialización: asociaciones, alianzas, coaliciones y redes, a la vez que producen orden. En esta dirección, para Melé (2016), un conflicto urbano es un productor social y territorial en la medida en que irrumpe en el espacio público; en la misma línea, para Fernandes (2008), es el proceso de producción de territorialidades a niveles material (los que se forman en el espacio físico) e inmaterial (en el espacio social); ambos inseparables.

En esta investigación nos interesa el conflicto "territorial", en donde el control del espacio juega un rol central. Se entiende la noción de territorios como espacios productores y producidos por distintas relaciones sociales que se disputan cotidianamente en contraposición a las visiones tradicionales de la geografía que tendieron a definirlo unidimensionalmente según una visión jurídica -en torno al control del estado-; una visión económica -como fuente de recursos- o como "soporte" en el que se desenvuelven relaciones sociales (Souto y Benedetti, 2011).

Por un lado, se repone en las dimensiones sociales, culturales y políticas; así, territorio es una categoría fundamental para comprender los procesos identitarios, los de poder y políticos que iluminan las prácticas y los sentidos que circulan (Torres, 2011) entre los diferentes actores sociales en tensión y disputa por el territorio. Por otro lado, se muestra la historicidad de esos espacios en conflicto; la huella de la sedimentación (Torres, 2011). En este sentido, los territorios no son pensados como espacios fijos y estáticos, sino como construcciones por y a partir de relaciones de poder, contingentes y cambiantes (Massey, 2004); como sus características, también se mencionan su multidimensionalidad y multiescalaridad (Fernandes, 2008), produciéndose multiterritorialidades, es decir, múltiples experiencias simultáneas y/o sucesivas de diferentes territorios (Haesbaert, 2011), siendo procesos constitutivos del entramado de relaciones sociales (Souto y Benedetti, 2011). 
Asimismo, la noción de lugar se considera para pensar los sentidos y significados diversos que se ponen en juego en torno a los terrenos ocupados. Para Souto y Benedetti (2011), el concepto de lugar está estrechamente ligado al de identidad; siendo el sentido de pertenencia al lugar un elemento clave para su definición. Por tanto, no es reducible a una localización, siendo un espacio existencial (Nogué, 2015). El lugar es pensado en relación con la experiencia de las personas con éste; no equivalente a inmovilismo; no necesariamente con fronteras precisas, como espacios conflictivos, donde la identidad es factible de reproducción a partir de diferentes fuentes (Massey, 2004).

Por su parte, de acuerdo con Massey (2004), el lugar adquiere sentido en tanto se vincula con el mundo más amplio; es decir, la identidad de un lugar no está arraigada simplemente en éste, sino que se construye en buena parte a través de relaciones de interdependencia que la vinculan a otros lugares. A la vez, cada lugar representa una mezcla distinta, un entretejido de relaciones sociales singulares diferentes a otros casos (Massey, 2005). Esto nos previene de las pretensiones homogeneizantes para observar las particularidades de los procesos socio-históricos y el desarrollo de un Neoliberalismo Realmente Existente (Brenner et al., 2015) que influye de diversas formas en los espacios urbanos, con procesos heterogéneos situados espacialmente de dominación y resistencias locales.

\section{El barrio como territorio(s) de política(s)}

NG constituye un barrio de la ciudad de Mar del Plata, un territorio particular delimitado administrativamente, en donde en su interior emergen diversas territorialidades y lugares de disputa (figura 1). El barrio, como inscripción social y territorial, funciona como un eje sintetizador de los procesos sociales espacializados, como una forma de localización espacial que nos delimita un contexto de interacciones y de identificaciones sociales, instituyendo un tipo de fronteras más claras o más difusas (Grimson, 2009). En tal sentido, el barrio es pensado en tanto categoría social referida al espacio y como un ámbito posible de "la política".

En este caso, la política es retomada como una categoría etnográfica (Ferraudi, 2014) para observar cómo se establecen y generan tanto la fijación de lazos y las estructuras de poder como las formas de categorización y de significación de jerarquías que tienden a vincularse con las propias modalidades de organización social (Grimson, 2009). Para ello, se retoma la propuesta de Borges (2004), pues considera a los barrios como espacios movidos por la política, lugares-eventos claves de la ciudad, y a los "lugareseventos" como categorías esenciales de la vida nativa que hacen referencia a lugares $u$ objetos que se manifiestan como acciones. Además, sugiere que, para hablar de política, es necesario recalar en lo que es vital en la vida social del barrio. 
Figura 1. Ubicación del Barrio Nuevo Golf, Mar del Plata, Buenos Aires

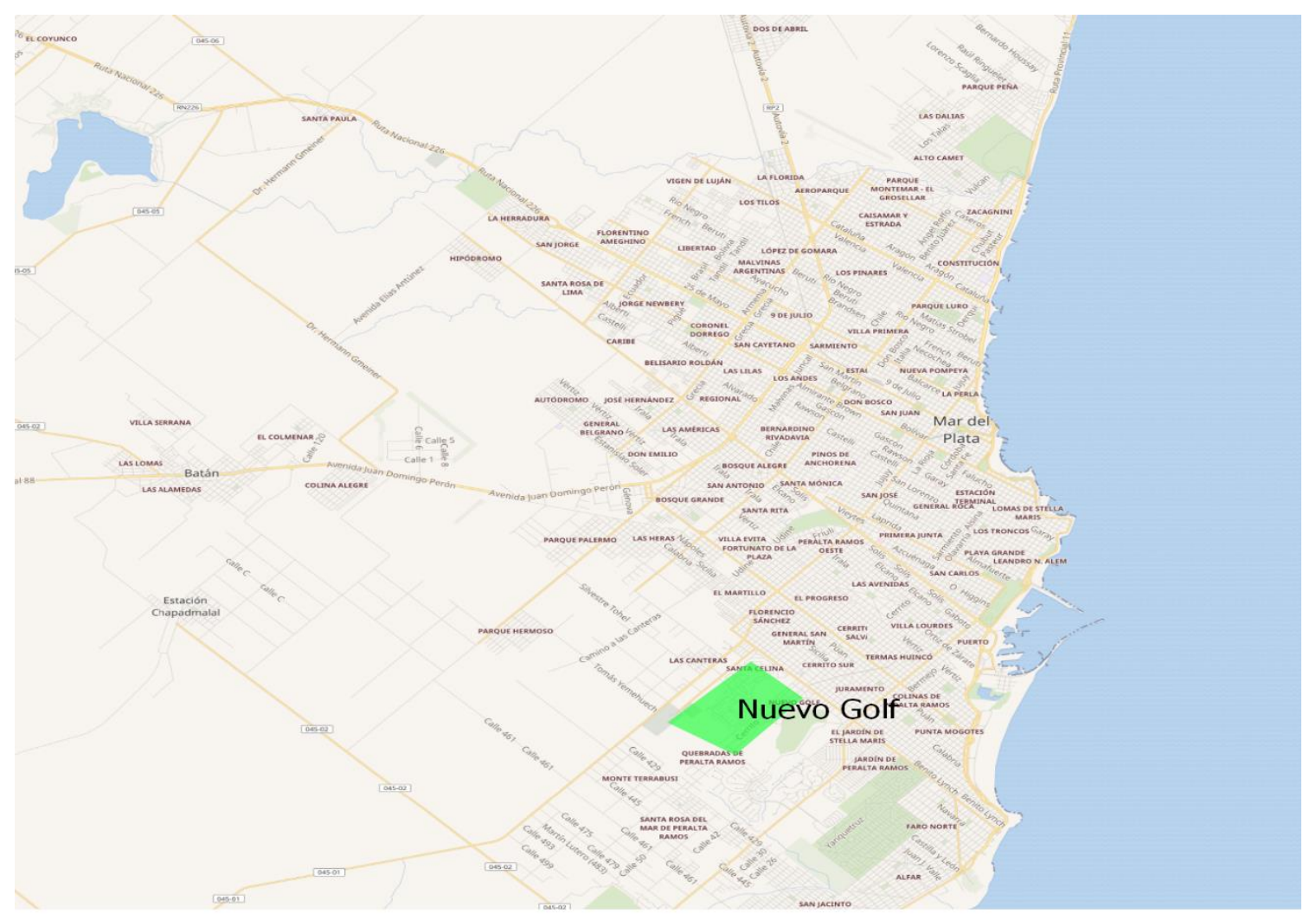

\section{Cambios territoriales en los márgenes. El barrio y la sociedad de fomento}

A continuación, se presentan algunas características del barrio y su proceso de configuración para comprender las condiciones de posibilidad y los entramados del barrio, a partir de dos "lugares-eventos": la conformación de la sociedad de fomento y el agua corriente. A la vez, se recupera el aporte de Lindón (2007) de pensar los conflictos urbanos poniendo énfasis en la centralidad del sujeto y la cuestión del movimiento. Como se verá, el barrio es construido por sujetos-habitantes y es pensado en movimiento; se concibe como el hacer cotidiano, las prácticas diversas y los lugares en donde se despliegan las prácticas. En el sujeto, en tanto que habita y se moviliza cotidianamente, es donde residen los fundamentos de ese movimiento o fluir constante en la ciudad (Lindón, 2010).

NG es uno de los barrios periféricos más populares de Mar del Plata; está ubicado en el periurbano suroeste y fundado sobre la ocupación "ilegal" de terrenos privados, ${ }^{2}$ loteados en la década de los 40. Está emplazada sobre una zona irregular, en tierras que pertenecían a la familia Peralta Ramos -fundadores de la ciudad, originada sobre la base 
de una ilegalidad (Nuñez, 2011) - y se eleva en una extensa loma hacia el sur. Aquí se observan las primeras "capas territoriales" o tipos de territorios (Fernandes, 2008): la presencia de concentración de tierra en manos de familias que fundaron la ciudad y que, hasta el día de hoy, inciden en la configuración de la ciudad. En este sentido, como señala Ratzel (en Schlogel, 2007), "en el espacio leemos el tiempo"; el proceso socio-histórico de producción de la ciudad aparece como un elemento significativo para la comprensión de un determinado espacio territorial.

El barrio es un termómetro de las crisis del país: las primeras ocupaciones, producto de una serie de ocupaciones de terrenos de manera irregular, surgieron a partir de mediados de los 90. En 2001, se pronunció esta situación poblándose masivamente. A partir de esta etapa, se consolidaron unas 700 familias en NG, lo que conformó una asociación vecinal. Así, se generó otra "capa territorial" a partir del acceso diferencial a los terrenos mediante ocupaciones o la generación de un mercado inmobiliario informal. En palabras de Mónica, quien gestiona un merendero desde que llegó a NG: "todos usurpamos, pagamos los terrenos, 70 pesos, se sabía que era así".

Este primer proceso de ocupación estuvo generado, entonces, por dos formas de acceso bajo una lógica de necesidad. En el caso de las ocupaciones colectivas o individuales, se priorizó el uso, y en el de la generación de un mercado inmobiliario informal, el ingreso mediante la venta de lotes de manera alternativa al mercado formal. Así empezaron a formarse las primeras viviendas o, como menciona Mónica, los primeros "ranchos": una categoría menor a la casa, que denota el proceso por el cual las familias primero se asentaban mediante la posesión de un terreno, armaban una casilla precaria y, posteriormente, iban construyendo la vivienda "como podían". Algo similar señala Cristian, quien está viviendo en el barrio desde hace tres años, luego de adquirir un terreno; menciona que la casa se está construyendo y que mientras vive en una casilla ahí mismo. O el caso de Carlos, quien le alquiló a un gendarme un espacio que no tenía ni baño ni agua y allí vivió con su familia (su esposa y cinco hijos) durante dos años mientras iba construyendo el baño; ahora consiguió un terreno y quiere construirse su casa.

Sin embargo, esta expansión poblacional no se detuvo y se incrementó de manera considerable a partir de dos nuevos procesos: uno originado en 2009 y otro posterior hacia finales de 2015. En su mayoría, provenían del norte del país -Santiago del Estero, Tucumán, Chaco- y contaban con familiares instalados en el barrio previamente. En el caso de los pobladores de 2009 a 2012, destaca la ubicación de lo que Fernando denomina "el borde del borde", es decir, la parte extrema hacia el sur de un barrio en las afueras del casco urbano.

En el caso de los últimos asentados en NG, algunos se ubicaron en esta zona "disputada" (figura 2), mientras que otros construyeron una casilla en un lote de algún familiar o compartieron el mismo techo con algún pariente ya instalado. Las composiciones familiares se diversificaron y extendieron en la misma vivienda o en otros 
espacios que se fueron anexando en el terreno de los primeros habitantes. Lo mismo ocurrió en relación con los hijos: en muchos casos y con motivo de formación de nuevos núcleos familiares, construyeron una vivienda atrás de la casa de sus parientes. En este sentido, al observar el barrio, se presentan diferentes territorios: la parte "consolidada" (en el centro) y los espacios en transformación (las nuevas ocupaciones hacia el final de la calle cerrito) o parte "disputada", motivo de ocupaciones colectivas o loteos informales para su venta. Estas diferencias no sólo se presentan espacialmente sino también por medio de las construcciones, calidad de las viviendas y la densificación de la zona.

Muestra de este proceso de expansión actual resulta el último Registro Nacional de Barrios Populares (RENABAP), ${ }^{3}$ donde unas 75 familias ubicadas en la parte sur, muy cerca de Quebradas de Peralta Ramos, forman parte del sector barrio beneficiario de un “certificado de Vivienda Familiar". Actualmente, NG alberga a más de 1,000 familias, muchas de ellas en condiciones de precariedad habitacional extremas.

\section{Figura 2. Zonas del barrio, actores y últimas ocupaciones colectivas. NG, Mar del Plata}

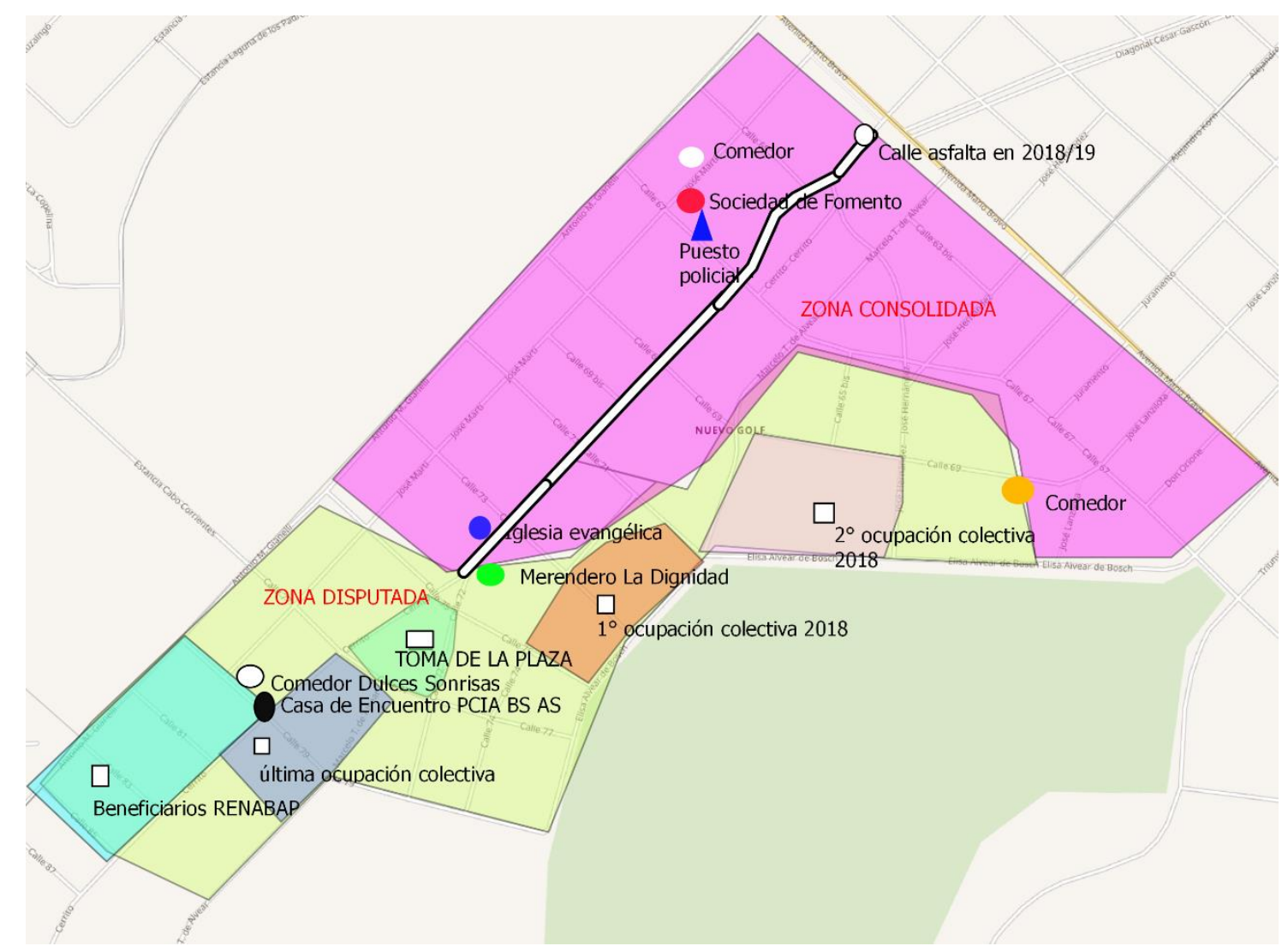

Fuente: elaboración propia.

${ }^{3}$ El registro se realizó en 2017 por distintas organizaciones sociales junto con el gobierno nacional; tuvo el objetivo de entregar un "Certificado de Vivienda Familiar" a los habitantes de asentamiento informales conformados con al menos ocho familias y que no cuentan con la propiedad del suelo ni con más de dos servicios básicos (agua corriente, electricidad, red cloacal, red de gas). 
En 2009, la Municipalidad del Partido de General Pueyrredon realizó un informe sobre la cantidad de asentamientos informales ${ }^{4}$ y villas en la ciudad; señaló el carácter de informalidad y precariedad en torno a la tenencia de la tierra de los habitantes de NG que se asentaban sobre tierras privadas pertenecientes a las distintas ramificaciones de la familia Peralta Ramos, principalmente. Es decir, la municipalidad no sólo construye el espacio barrial a partir de sus "ausencias-presencias", sino que también lo hace mediante la caracterización del "territorio-lugar": no es un barrio, es un asentamiento informal. Durante los últimos años, hubo un impulso por parte de la sociedad de fomento, en connivencia con concejales, funcionarios municipales y la empresa Cabo Corrientes S.A., de llevar a cabo un proceso de regularización dominial en el barrio. Sin embargo, en la actualidad, aún no ha tenido un desarrollo exitoso.

Con el crecimiento y la expansión territorial, aparecieron las primeras referencias barriales, como la sociedad de fomento. Según señalan Pablo y Lucas, ${ }^{5}$ cuando se mudaron al barrio, la institución vecinal se dedicaba "a la venta de agua". Pablo recuerda que la sociedad de fomento, en 2001-2002, tenía un tractor y se utilizaba para transportar y vender agua "casa por casa". La imagen de este espacio vecinal estaba ligada, entonces, a un negocio obtenido de la venta de un bien que escaseaba en el asentamiento y que obtenían "de una canilla que estaba por la avenida (Mario Bravo) y cerrito".

Por esos años, el espacio vecinal funcionaba en "la casa de Miguel”, quien comandaba la junta vecinal. En realidad, dice Pablo, no era una casa, sino una casilla rodante instalada sobre la calle 79 y cerrito. "Después Miguel se hizo la casa". En tanto, señala Mónica, la sociedad de fomento siempre se dedicó a hacer "política" pero antes era peor. $\mathrm{Su}$ recuerdo viene atravesado por algo que Rodrigo también menciona: ante la situación de necesidad, los únicos beneficiarios de las reparticiones de mercadería realizadas por la junta vecinal eran quienes acompañaban en las actividades, "los que iban al corte de calle, a las marchas... eran punteros". Debido a esta situación, Mónica gestionó el "roperito y el merendero" en su casa, en contraposición con el uso político de la necesidad.

Con el tiempo, otros vecinos se organizaron y se hicieron cargo de la junta vecinal, la cual empezó a funcionar en la casa de Rodolfo. Según menciona Pablo, Rodolfo utilizaba los recursos de la sociedad de fomento para el comercio de leña. Sin embargo, en 2011, mientras talaban un árbol, cayó sobre una mujer provocándole la muerte. Este hecho terminó con el negocio personal de la venta de leña a través de la sociedad de fomento.

\footnotetext{
${ }^{4}$ La utilización de "informal" deriva de la designación aplicada a los trabajadores no registrados. En este sentido, la "informalidad" vendría a estar representada por la falta de títulos de propiedad o posesión. Por lo general, los asentamientos informales presentan un trazado urbano regular y planificado y son el resultado de un proceso de organización colectiva (Cravino, 2008).

${ }^{5}$ Se modificaron los nombres para resguardar la identidad de los entrevistados y de las organizaciones barriales.
} 
Posteriormente, Lucas y otros vecinos lograron conformar una junta vecinal sin personería jurídica, lo cual se obtuvo hace dos años aproximadamente. Se estableció en la casa de Lucas y las referencias que hacen es de gestión del barrio. Allí también funciona el espacio de organización "La barricada", en donde se realizan actividades diversas. Los miércoles, por ejemplo, su casa se transforma en una "salita" de atención médica con la presencia de personal del programa de Atención Primaria de la Salud para áreas rurales.

En 2014-2015 la sociedad de fomento inició una "Mesa de gestión" con la municipalidad para llevar a cabo un proceso de regularización dominial de quienes habitan en los terrenos pertenecientes a la familia Peralta Ramos. Sin embargo, en la actualidad, sólo dos de los que iniciaron el trámite administrativo obtuvieron el título de propiedad. Ante la pregunta de si era una demanda de los habitantes, Pablo mencionó que la municipalidad les había exigido iniciar este proceso para llevar a cabo intervenciones estatales en la zona. En primera instancia, en 2013, realizaron un relevamiento del barrio junto a miembros de un grupo de extensión de la Facultad de Salud y Trabajo Social de la Universidad Nacional de Mar del Plata; posteriormente, en 2015, obtuvieron uno de los logros de "gestión" más importantes para el barrio: el agua corriente, extendida por Obras Sanitarias Sociedad de Estado.

Antes del agua corriente, Romina recuerda comprarle agua al de la sociedad de fomento cuando acaba de llegar al barrio hace 15 años: "no me acuerdo el nombre, pero pasaba por casa". Si bien es un paso importante en el acceso a los bienes e infraestructura, la cotidianidad barrial muestra cierto funcionamiento defectuoso del servicio. Los entrevistados mencionan que el agua escasea durante el verano; incluso, es muy probable que no haya en días de calor. Por eso, Marta -del comedor "Mañanitas" - junta agua por las noches -si es que hay- para prever su provisión para el día siguiente, ya que es un lugar donde asisten muchos chicos del barrio; aunque -cometa- "mucho espacio no tengo, tampoco". Otras situaciones comunes en el barrio son los caños pinchados y las pérdidas de agua. Varias veces al año, OSSE debe intervenir en alguna parte de NG para solucionar este problema. Por lo tanto, el corte del suministro del bien es constante.

\section{El territorio en pugna: condiciones de posibilidad para la territorialización}

En Inglaterra, en el siglo XVIII, Thompson (1971), en su texto "Economía moral de la multitud", muestra cómo en tiempos de precios muy altos la "multitud" podía imponer cierto control del mercado y de los precios; a la vez, demuestra cómo el concepto de motín impedía una lectura de otros hechos que también servían para entender los procesos sociales intervinientes en la sociedad de esos tiempos como un término que podía ocultar más de lo que revelaba. Había otros métodos, como: la petición en masa a los gobernantes; los días de ayuno, sacrificios y plegarias; la migración de poblados enteros. 
Por otro lado, el autor señala a la acción como un hecho racional y que no tenía lugar entre las personas desamparadas, sino entre los grupos que se percataban que tenían un poco de poder para ayudarse a sí mismos cuando los precios subían (Thompson, 1971). Así, el "motín" no resultaba una respuesta "natural" al hambre, sino una compleja pauta de comportamiento colectivo alternativa a las estrategias individualistas y familiares: el hambre no dicta que deban amotinarse ni determina las formas del motín.

Thompson, por un lado, nos invita a pensar las condiciones de posibilidad para el desarrollo de cierta acción, no sólo ligada a condicionantes estructurales, sino también a trayectorias sociales y a la agencia de los actores, a las disputas, correlaciones de fuerzas y asociaciones cambiantes dentro de un determinado campo de fuerzas; en este sentido, el "hambre" o la "necesidad" no son por sí solos motores para generar un proceso de acción colectiva. Por otro lado, vemos cómo categorías homogeneizantes como "motín" o "lucha por el acceso a la tierra" o "política" invisibilizan los procesos sociales y entramados generados en un determinado momento socio-histórico.

El caso de la toma en NG es imposible entenderlo fuera del contexto nacional y local. En términos generales, posterior a la crisis de 2001, se generó un crecimiento económico a tasas elevadas. Sin embargo, los sectores medios y bajos siguieron encontrando dificultades para acceder al suelo y a la vivienda (Kessler, 2014), aun considerando la relativa mejora en sus ingresos. Esta situación trajo consigo un aumento de la inquilinización y una densificación de villas y asentamientos. Es decir, hubo una disminución de la brecha de desigualdad que no se tradujo en el espacio urbano, manteniéndose un patrón de urbanización excluyente (Segura, 2014). En Mar del Plata, alrededor del 17\% de los habitantes alquila una vivienda y, en 2016, alrededor de 7,000 familias vivían en asentamientos informales o villas.

Asimismo, otra de situación que adquiere centralidad en la dinámica socio-espacial actual es la situación laboral que atraviesa la mayor parte de la población marplatense. Por un lado, Mar del Plata es la principal ciudad con mayor índice de desempleo del país. ${ }^{6}$ A la vez, la cuestión de la estacionalidad laboral es otro de los datos centrales y que incide en la constitución de un trabajador temporal altamente precarizado. Las principales fuentes de empleo en Mar del Plata, tanto las ligadas al turismo -gastronomía, hotelería, principalmente- como la portuaria, la construcción y la producción hortícola, se sostienen sobre la base de una marcada estacionalidad del trabajo que caracterizan a las formas de contratación como fuertemente inestables, flexibles e inciertas.

Por su parte, la estructura de la propiedad de la tierra también es un factor crucial para entender la dinámica urbana local. Como ya se mencionó, Mar del Plata fue fundada a partir de una transgresión a la ley vigente de ese momento, y se estableció sobre tierras privadas y no fiscales (Nuñez, 2011). Este hecho no sólo generó un encarecimiento

${ }^{6}$ Según el Instituto Nacional de Estadística y Censo (INDEC) del cuarto trimestre de 2017, la ciudad registró un 9.3\% de desempleo por encima del promedio nacional -de7.2\%-. 
significativo de los valores de la tierra, sino que también produjo la escasez de terrenos fiscales. Esta cimentación fundante del orden social ${ }^{7}$ es uno de los tantos alicientes generadores de una división social del espacio que prevalece en la actualidad.

\section{El territorio, ¿plaza o tierra fiscal?}

El sábado 5 de mayo de 2018, un grupo de 43 familias, aproximadamente, ocupó un sector del barrio NG. A diferencia de las anteriores apropiaciones realizadas en menos de dos semanas, ésta fue denunciada por el presidente de la sociedad de fomento. El hecho se tornó público y derivó en diferentes estrategias de legitimación o deslegitimación. Según lo señalado por Lucas, el lugar ocupado pertenece a un espacio destinado a una plaza pública, en donde iban a construir, además, una salita de primeros auxilios y una guardería. También, menciona que este espacio era un pulmón verde muy importante para el barrio, y que había sido tomado por una organización y se estaba llevando a delante una venta ilegal de terrenos. Así, el 7 de mayo, Lucas presentó una carta al secretario de gobierno municipal señalando la situación en la que se encontraba el espacio público. Ante la denuncia, los medios de comunicación fueron convocados a cubrir la demanda social.

A diferencia de las anteriores ocupaciones, entonces, se inician diversos procesos de construcción de identidades y territorios. Así, diferentes noticias circularon mostrando, por un lado, la preocupación planteada por Lucas y, por otro lado, la demanda habitacional de un grupo de personas caracterizadas como "madres jefas de hogar, desempleadas y con muchos hijos a cargo". La voz de los ocupantes estuvo mediatizada por Andrea, del Movimiento LD, quien señaló la "necesidad" de este grupo de "madres", quienes, ante la crisis del puerto y el problema habitacional, decidieron tomar las tierras que consideraban "fiscales".

Para Andrea, no sólo eran terrenos fiscales, sino también un sector que significaba el peligro y la inseguridad: "era un basural, pastos largos, una boca de lobos" y "no eran de nadie". Ahora, representaba una mejora y una posibilidad de acceso a la tierra y a la vivienda. Desde principios de año -menciona-, empezaron a hacer trabajo territorial con la organización: el funcionamiento de un merendero en su casa y la realización de un evento de boxeo. Matías -uno de los referentes de LD a nivel local- señala que la organización llegó después de la toma, que políticamente no les conviene pero que "bancan" porque es una "reivindicación social".

\footnotetext{
${ }^{7}$ Esta ilegalidad fundante de la ciudad fue articulada con la reconversión de las tierras rurales a urbanas y la construcción de un balneario de veraneo en reemplazo de la actividad saladeril (Núñez, 2011); principales ejes de ordenamiento social que establecieron una primera configuración socio-espacial de la ciudad. Así, a principios del siglo XX, Mar del Plata se promocionó en los sectores de la elite porteña como la Biarritz local homologando parte de su fisonomía. El modelo de "balneario" conllevó un proceso de ordenamiento social para garantizar la exclusividad del lugar. Las familias de inmigrantes -principalmente italianos que realizaban actividades de pesca- fueron desplazadas del núcleo urbano en donde se encontraban mediante ordenanza municipal por su "mala imagen, olores, casillas de baja calidad"
} 
A pesar de la denuncia realizada por un grupo de personas, la Fiscalía No. 12 desestimó que hubiera "usurpación" pues no hubo violencia en la ocupación. Este acto impidió el desalojo de la toma, aunque la denuncia activó otras situaciones: "incertidumbre" y peligro de "desalojo", volverse pública, presencia policial cuando Lucas mostró que la zona figuraba como plaza, venta de terrenos, así como que nuevos ocupantes, anteriores ocupantes en realidad, recibieron dinero a cambio, algunos tildados de prófugos y otros de "vendedores de drogas"; todo ello generó un desborde de la situación para LD.

Los efectos de la denuncia no sólo derivaron en la aparición pública de los actores implicados en la toma, sino también en la generación de diferentes actividades para legitimarla. Así, a mediados de mayo, organizaron una radio junto a miembros del partido político PG, "ollas populares" -las cuales fueron convocadas, pero suspendidas por mal tiempo-, también realizaron una intervención las familias de la organización "Sin Techo" al construir una casilla en los terrenos. A la par, realizaron asambleas entre los ocupantes para planificar algunas cuestiones en torno a la ocupación y, como mencionó Andrea, para "conocerse".

Hacia fines de mayo se realizó una de las últimas intervenciones públicas, y Andrea, en medio del acto llevado a cabo por la Marcha Federal en el centro de la ciudad de Mar del Plata, mencionó tener "43 familias a cargo". Posteriormente, decidieron invisibilizar la situación, "no hacer ruido", por lo que suspendieron las actividades y las convocatorias a organizaciones como los "Sin Techo" o PG. Ante la insistencia de uno de los miembros de la ocupación para convocarlos, Andrea y Carolina -también integrante de LD- mencionaron que, si los invitaban, iban a querer quedarse con una parte de esos terrenos.

\section{El multiterritorio-lugar constituido en la puja entre actores sociales}

Como sostiene Simmel (2010), el conflicto activó redes de relaciones y asociaciones entre diferentes actores sociales: no sólo debe aprehenderse a éste como una crisis, sino también como una forma positiva de socialización a partir de la producción de asociaciones, vínculos, redes. En este sentido, la denuncia activó una serie de lazos y asociaciones previas y nuevas entre los actores implicados y otras organizaciones vinculadas a procesos de lucha por el acceso a la tierra que fueron variando con el paso del tiempo.

Lucas, como parte de sus diligencias en la sociedad de fomento y en "La barricada", entró en contacto con organizaciones como PG, la cual lleva a cabo acciones en torno a la intervención del hábitat. No son los únicos que participan en las diferentes actividades, pero sí los que se vieron envueltos en una situación conflictiva al estar en relación con ambas partes en disputa: PG conforma un frente a nivel nacional con LD. Ante la denuncia del PSF, decidieron apoyar la "lucha por el acceso a la tierra". Sin 
embargo, no fueron los únicos cambios: el hecho de decidir invisibilizar la toma, llevó a LD a moderar los lazos de solidaridad propuestos por PG y los "Sin Techo". El PSF debió cambiar la estrategia. Empezó a circular en el barrio la idea de que se estaba armando una "villa" y que quienes la estaban ocupando en realidad no la necesitaban, sino que vendían los terrenos y, además, no eran del barrio. Los ocupantes, a decir de una vecina, se creían "terratenientes" y "usurpaban" un espacio público de "todos". Así emergía, la estigmatización y la diferenciación por medio de la categoría "villa" como lo peligroso y no deseado, compuesto por personas vinculadas a actividades ilegales, en contraposición al "barrio"; y, por otro lado, la categoría de "terratenientes" nos muestra la deslegitimación del proceso por medio de ligar el proceso a la generación de un mercado de tierras informales, hecho que se complementa con su no-pertenencia al territorio en disputa.

A su vez, en agosto, el PSF realizó dos asambleas en la sociedad de fomento en la que fue convocado el agente inmobiliario "Marcone", administrador de los terrenos de las diferentes ramificaciones de la familia Peralta Ramos. Allí, el agente inmobiliario se comprometió a "permitir" la ocupación de los terrenos que se encontraban lindantes al sector en conflicto, y que pertenecían a los Peralta Ramos. A largo plazo, iban a poder solicitar a la municipalidad la expropiación de los terrenos. De esta forma, en agosto se inició un nuevo proceso de ocupación de terrenos motorizado por el PSF y sobre tierras privadas; se contó con la aprobación del administrador. También otro sector del barrio fue ocupado y desalojado porque estaba sobre calles. Ante esta situación, la Fiscalía los desalojó.

\section{Hacia el interior de la toma: la construcción del legítimo ocupante}

Más allá de la imagen homogeneizante que pretendían imponer los referentes de LD sobre los ocupantes, las personas que participaban de la toma presentaban diversos intereses y estrategias en torno a la ocupación de los terrenos. La idea de necesidad funcionaba como eje aglutinador, sin embargo, no permitía visibilizar las complejidades de los casos. En este sentido, la construcción del legítimo ocupante venía dada por un discurso exterior -es decir, por la organización social LD- que intentaba controlar la situación de una ocupación de tierras, donde un grupo de familias se encontraba (des)articulado por una posibilidad alternativa de acceso a la tierra y a la vivienda. La organización, quien impulsaba la toma, introdujo la idea de "lucha por el acceso a la tierra y a la vivienda". 
Desde las primeras asambleas realizadas en la casa de Andrea surgieron inconvenientes sobre quiénes eran los que estaban ocupando, dónde estaban los que faltaban y por qué no respondían los mensajes de "Whatsapp" del grupo creado entre los ocupantes. Las listas del cuaderno de Andrea no coincidían con los presentes y siempre se agregaba alguien que no estaba anotado. También, muchos se anotaban en el terreno de algún pariente para subdividir.

Se estableció la oposición entre "los que necesitan" y los que "no necesitan"; en varias reuniones, se planteó que muchos no estaban presentes en las reuniones y que en realidad no necesitaban un lote para construir su casa. Dentro de los que "no necesitan", estaban los "vecinos con casa": ya tenían una vivienda propia y querían otro espacio para "cuidar sus caballos" o para alquilar o vender. También estaban los que "venden" sus terrenos, es decir, querían un terreno para generar un ingreso económico. Por último, quizás los más conflictivos por la imagen que se exteriorizaba, estaban los "ilegales", divididos entre los que estaban "prófugos" de la ley por haber cometido un delito, y los que "vendían drogas".

Esta variedad de personas englobadas dentro de la figura de los que "no necesitan" eran presentados como "tomadores ilegítimos" y, por lo general, no participaban en las reuniones, y no todos los conocían por lo que las referencias a éstos eran constantes. O alguien nuevo se presentaba a la reunión porque le habían ofrecido comprar un terreno o ya le había comprado a alguien uno. Asimismo, esta diferenciación mostraba que las "estrategias" habitacionales variaban hacia el interior de los participantes: no había un único "sentido" en torno a la toma de los terrenos $\mathrm{y}$, en algunos casos, surgía la posibilidad de generar un mercado inmobiliario informal como estrategia habitacional.

Dentro de los que "necesitan" también se generaba una distinción: los que "tenían terrenos" y los que "están fuera y quieren terreno". Estos últimos habían empezado a participar en las reuniones con la intención de lograr su cometido. En alguno de los casos, el contacto lo habían realizado por medio de uno de "los que no necesitan" y que "vendían sus terrenos"; al respecto, la postura de la organización era ocupar los terrenos, pero sin pagar, porque "los terrenos no pertenecían a nadie".

La construcción de legitimidad de los que ocuparon los terrenos y se enmarcaron dentro de la idea de "los que necesitan" estaba signada por varios motivos: primaban las complicaciones de pago de alquiler, la cohabitación de varios núcleos familiares en una vivienda y el hacinamiento; pero también la ampliación de los espacios de habitación y la mejora en la calidad de vida de sus hijos, la planificación a futuro y la casa propia, principalmente. Es decir, la legitimidad de la apropiación de los terrenos estaba signada por la "necesidad" de tener una vivienda como un argumento moral central para justificar la toma (Perelman, 2017), pero, en la práctica, la posibilidad de acceso alternativa a la tierra y a la vivienda motorizaron una acción individual, aunque colectivizada. Por consiguiente, el elemento colectivo surge con el conflicto, no es anterior. 


\section{Reflexiones preliminares}

El trabajo presentado planteó algunos interrogantes en relación con el conflicto urbano y las condiciones de posibilidad para el desarrollo de una ocupación de terrenos en el barrio NG. En primer término, se señalan algunas consideraciones en torno a la forma de caracterizar los terrenos de manera diferencial por parte de los actores involucrados. Para el PSF, los terrenos ocupados son un lugar pensado como plaza. Su referencia está ligada a la experiencia previa en territorio por su trayectoria barrial, contando con conocimiento jurídico de los terrenos. A su vez, en su discurso, también despliega cuestiones vinculadas con las emociones y la identidad barrial: la necesidad y la proyección de construcción de una salita y una guardería expresa un conjunto de objetivos y de saberes prácticos (Lindón, 2010) ligados a demandas sociales de los habitantes.

Para las familias que participaron de la toma no existe un sentimiento de pertenencia ni de identidad con respecto a los terrenos, aunque sí un significado establecido por la posibilidad alternativa de acceso a la tierra, el cual está generado a partir de considerar el espacio como "tierra fiscal", "sin propiedad", "de nadie".

Para la organización involucrada en la ocupación, esos terrenos representan un espacio para su territorialización política. Si bien, en un principio, la estrategia estuvo vinculada a invisibilizar el proceso y a los sujetos, posterior a la denuncia, se generó una postura tendiente a visibilizarlos en torno a la figura de "madres con muchos hijos a cargo" en una situación de necesidad. Esta construcción de una identidad común presentó una amalgama de casos y situaciones hacia el interior del conjunto de familias, produciéndose la construcción del legítimo ocupante. Sin embargo, los participantes muestran una heterogeneidad de casos y de referencias respecto a las estrategias habitacionales que ponen en cuestionamiento la enmarcación del hecho con relación a una situación de "necesidad". En este sentido, las nociones de "necesidad" o de "lucha por el acceso a la tierra" no permiten comprender el fenómeno, siendo un proceso vinculado a una posibilidad alternativa de acceso a la tierra. Es decir, el legítimo ocupante se construye después de la denuncia, sobre la base de la "necesidad" y en torno a la "lucha por el acceso a la tierra".

A su vez, se advierte la multiterritorialidad (Haesbaert, 2011) que emerge de la disputa por el control de los terrenos. Posterior a la denuncia, la organización social intentó construir una identidad de las familias, aunque no logró consolidarse. Ante el conflicto o la presencia policial, las familias se dispersaron, y no poseían herramientas de contención ni mantención de la ocupación. Esto derivó en otras situaciones como la venta de terrenos y nuevos ocupantes. 
Por un lado, observamos una desorganización de la ocupación y la falta de una estrategia colectiva y, por otro lado, el componente político sólo viene "dado" desde la organización que motoriza la ocupación, no así de las familias que ocuparon. Lo que nos abre algunos interrogantes a la hora de pensar el espacio territorial y las disputas en torno a los terrenos. ¿Hasta dónde "la política" de las organizaciones barriales responde a demandas sociales -en este caso centrada en el problema de acceso a la tierra- por sobre los intereses de territorialización de la organización?

El desconocimiento de la trama relacional del barrio y del carácter jurídico de los terrenos pone en jaque a la organización que participa de la ocupación. Sin embargo, la situación de abandono de los terrenos, ¿problematiza la acción de la organización barrial o muestra la posibilidad de apropiación de un espacio territorial que había sido pensado como una plaza pero que en la práctica era un "lugar" inseguro o abandonado? A la vez, ese espacio abstracto representado en los mapas de la municipalidad como "plaza" ¿no estaría mostrando lo que señala Lefebvre (1974) como el pasaje de ese espacio "abstracto", "instrumental", a un espacio otro-diferencial producido en su interior, relacionado con los usos y las prácticas de los habitantes?

Por otro lado, la construcción territorial no sólo se da a partir de las presencias estatales -hecho que muestra cómo los actores definen a los terrenos en torno a su condición jurídico-estatal (como plaza o como tierra fiscal) y la utilización de diferentes recursos (como el mapa del barrio)-, sino también de sus ausencias. Es decir, los barrios en los márgenes son una forma de generar territorios difusos donde el estado aparece de manera ilegible; en este caso, encarnado en la denuncia del presidente de la sociedad de fomento $\mathrm{y}$, posteriormente, con la presencia del secretario de gobierno y el intento de desalojo, a pesar de que la Fiscalía desestimara el delito. Sin embargo, la ilegibilidad del estado es la que da un margen de acción a los ocupantes quienes inician un proceso de territorialización a partir del conflicto.

A su vez, el barrio presenta determinadas condiciones de posibilidad para el acceso alternativo a la tierra que lo vuelve un territorio diferencial a otros barrios de la ciudad, habiendo una disputa constante por el control y la apropiación de los terrenos. De esta forma, se observan diferentes lecturas territoriales -prevaleciendo la estatal- y su superposición, como territorios-lugares en constante transformación atravesados por la política barrial y la puja de éstos como un elemento constitutivo de la ciudad en los márgenes.

\section{Referencias}

Borges, A. (2004). Tempo de Brasília. Etnografando lugares-eventos da política. Río de Janeiro: Relume Dumará Brenner, N., Peck, J. y Theodore, N. (2015). “Urbanismo neoliberal. La ciudad y el imperio de los mercados" En: Observatorio Metropolitano de Madrid (Ed.), El mercado contra la ciudad. Globalización, gentrificación y políticas urbanas. Madrid: Traficantes de sueños 
Cravino, M. C. (2008), Los mil barrios (in)formales. Los Polvorines, Buenos Aires: Universidad Nacional de General Sarmiento.

Fernandes, M. (2008). Sobre la tipología de territorios. Recuperado de: http://acciontierra.org/IMG/pdf/BERNARDO_TIPOLOGIA_DE_TERRITORIOS.pdf

Ferraudi, C. (2014). Ni punteros ni politicos. Urbanización y politica en una villa del conurbano. Buenos Aires: Ed. Gorla

Grimson, A. (2009). La vida política en los barrios populares de Buenos Aires. Buenos Aires: Prometeo

Haesbaert Da Costa, R. (2011). El Mito de la Desterritorialización. Del fin de los territorios a la multiterritorialidad. México: Siglo XXI Editores.

Kessler, G. (2014). Controversias sobre la desigualdad. Argentina, 2003-2013. Buenos Aires: Fondo de Cultura Económica.

Lefebvre, H. (1974). La producción del espacio. Papers. Revista de Sociologia, 3, $219-229$. doi:http://dx.doi.org/10.5565/rev/papers/v3n0.880

Lindón, A. (2010). “Invirtiendo el punto de vista: las geografías urbanas holográficas del sujeto habitante" En Lindón, A. y D. Hiernaux, Los giros de la Geografía Humana. Desafíos y Horizontes, Barcelona: Antrophos, pp.175-200.

Lindón, A. (2007). El constructivismo geográfico y las aproximaciones cualitativas. Revista de geografía Norte Grande, (37), 5-21. https://dx.doi.org/10.4067/S0718-34022007000100001

Massey, D. (2005). “La filosofía y la política de la espacialidad: algunas consideraciones”. En Arfuch, L. (comp.): Pensar este tiempo. Espacios, afectos, pertenencias, Buenos Aires: Paidós

Massey D. (2004). Lugar, identidad y geografías de la responsabilidad en un mundo en proceso de globalización. Treballs de la Societat Catalana de Geografia, 57, 77-84. Recuperado de: https://publicacions.iec.cat/repository/pdf/00000019/00000025.pdf

Melé, P. (2016) “¿Qué producen los conflictos urbanos?” En: Carrión, F. y Erazo, J. (Coord.) El derecho a la ciudad en América Latina. Visiones desde la política, México: CLACSO

Nogué, J. (2015). Sentido del lugar, paisaje y conflicto. Geopolitica(s). Revista de estudios sobre espacio y poder, 5(2), 155-163. https://doi.org/10.5209/rev_GEOP.2014.v5.n2.48842

Núñez, A. (2011), Miserias de la propiedad. Apropiación del espacio, familia y clase social. Mar del Plata: Eudem

Perelman, M. (2017). Construyendo la legitimidad: Esperas y argumentos morales en la toma del Parque Indoamericano de la Ciudad de Buenos Aires. Dilemas - Revista de Estudos de Conflito e Controle Social, 10(2), 241-258. Recuperado de https://revistas.ufrj.br/index.php/dilemas/article/view/10596

Segura, R. (2014). El espacio urbano y la (re)producción de desigualdades sociales. Desacoples entre distribución del ingreso y patrones de urbanización en ciudades latinoamericanas, desiguALdades.net. Working, 65, Recuperado de: https://www.academia.edu/20289435/El_espacio_urbano_y_la_re_producción_de_desigualdades_s ociales._Desacoples_entre_distribución_del_ingreso_y_patrones_de_urbanización_en_ciudades_latin oamericanas

Simmel, G. (2010). El conflicto. Sociología del antagonismo. Madrid: Sequitud

Schlogel, K. (2007). En el espacio leemos el tiempo, Madrid: Siruela.

Souto, P. y Benedetti, A. (2011). “Pensando el concepto de lugar desde la geografía". En: Souto, P. (comp.) Territorio, lugar, paisaje. Prácticas y conceptos básicos en geografía. Buenos Aires: Editorial Facultad de Filosofía y Letras Universidad de Buenos Aires.

Thompson, E. (1991). “Economía moral revisada” En: Costumbres en común, Barcelona: Crítica

Torres, F. (2011). Territorio y lugar: potencialidades para el análisis de la constitución de los sujetos políticos. El caso de un movimiento de desocupados en Argentina. Geograficando, 7 (7), 209-238. Recuperado de: http://www.memoria.fahce.unlp.edu.ar/art_revistas/pr.5099/pr.5099.pdf 